\section{BMJ Open}

Ophthalmology

\title{
Danish teleophthalmology platform reduces optometry referrals into the national eye care system
}

\author{
Danson Vasanthan Muttuvelu (D) , ${ }^{1,2}$ Heidi Buchholt, ${ }^{3}$ Mads Nygaard, ${ }^{3}$ \\ Marie Louise Roed Rasmussen, ${ }^{1}$ Dawn Sim $^{4,5}$
}

To cite: Muttuvelu DV, Buchholt H, Nygaard M, et al. Danish teleophthalmology platform reduces optometry referrals into the national eye care system. BMJ Open Ophthalmology 2021;6:e000671. doi:10.1136/ bmjophth-2020-000671

Received 27 November 2020 Revised 2 March 2021 Accepted 3 March 2021

\section{Check for updates}

C) Author(s) (or their employer(s)) 2021. Re-use permitted under CC BY-NC. No commercial re-use. See rights and permissions. Published by BMJ.

${ }^{1}$ Department of Ophthalmology, Copenhagen University Hospital, Kobenhavn, Denmark ${ }^{2}$ mitØje ApS, Aarhus, Denmark ${ }^{3}$ Specsavers Optical Group Ltd, Aalborg, Denmark ${ }^{4}$ Moorfields Eye Hospital City Road Campus, London, UK ${ }^{5}$ University College London, London, UK

Correspondence to Dr Danson Vasanthan Muttuvelu; dansonvm@gmail.com

\section{ABSTRACT}

Objective The purpose of this study was to evaluate the stratification of follow-up and referral pathways after implementation of a systematic cloud-based electronicreferral teleophthalmological service for optometryinitiated ocular posterior segment disease referrals to the Danish national eye care system.

Methods and Analysis A retrospective cohort study was conducted in the period from 1 August 2018 to 31 July 2019. Patients with suspected ocular posterior segment disease reviewed by the telemedical ophthalmology service were included. The service stratified patients into the categories: no need for follow-up, followup by optometrist, follow-up by the telemedical service and referral to the national Danish eye care service. Results From a pool of 386361 customers, 9938 patients were enrolled into this study. $19.5 \%$ of all patients were referred to the Danish national eye care system, while $80.5 \%$ of the patients in the telemedical service were not, in the period from 1 August 2018 to 31 July 2019. $14.4 \%$ of the optometrist referrals did not need any follow-up, while a majority of $66.1 \%$ needed some followup either by the optometrist themselves or within the telemedical service.

Conclusion Optometrist posterior segment disease referrals can be considerably reduced with a risk stratified approach and optimal use of technology. New models can improve and streamline the healthcare system.

\section{DANISH TELEOPHTHALMOLOGY PLATFORM RISK STRATIFIES REFERRALS FROM OPTOMETRIST TO OPHTHALMOLOGIST}

Healthcare systems differ across the world according to the needs, demands and the economy of each country. ${ }^{1}$ The Danish Healthcare System is built on a universal welfare-based model, and is further grounded on a hierarchical medical system. The general ophthalmologist (the primary sector) maintains the gatekeeper function to refer relevant patients to the secondary sector (general eye departments) or the tertiary sector (university eye clinics). General practitioners (GPs) and optometrists frequently refer to the general ophthalmologist, but according to the Danish patient protection act, all citizens

\section{Key messages}

What is already known about this subject?

- The number of patients in eye care has risen dramatically during the last two decades. Optometrists are a well-known referral partner, and different strategies (eg, education and implementation of guidelines) have been evaluated. However, there is only very limited knowledge of how implementation of state-of-the-art cloud-based e-health models can impact the referrals to the ophthalmologists.

\section{What are the new findings?}

$>$ This is the largest real-world e-health-based optometry-opththalmology study. It demonstrates a new industry standard with a fully functioning ehealth-based ophthalmology service that drastically reduce referrals to the national healthcare system, as well as enacts measures for telemedical followup systems.

How might these results change the focus of research or clinical practice?

This study demonstrates that new digital healthcare models, which focus on a risk-stratified approach with optimal use of technology, change of working patterns and continuous education, can further optimise the healthcare system.

have the right to seek an appointment themselves without any referral. Unlike in the UK, a country with similar welfare-based model, Danish optometrists are not part of the Danish Healthcare System. ${ }^{2}$

Though the Danish optometrists were recognised as healthcare providers by the Danish Patient Safety Authority in 1994, it was not before 2007 that optometry was established as a professional bachelor's degree with a master's programme in 2014. Danish optometrists are partly trained in slit-lamp funduscopy along with common fundus pathologies in their bachelor's degree and contain the right to diagnose, but neither master or bachelor optometrists have the right to use mydriacs or therapeutic ophthalmic drugs. Danish optometrists hold various 
positions in the national eye care system as well as the private eye care industry: monitoring patients preoperative and postoperative care in cataract surgery, refractive surgeries, AMD management, diabetes management, glaucoma monitoring. However, the vast majority of optometrists are employed in optical retail industry. Thus, there is a wide-ranging discrepancy in competence level across the profession. ${ }^{3}$

In a global perspective the optometrist role is indeed varying from nation to nation. The optometrists' role in the UK have increased during the past decades due to a growing clinical demand along with constraints on the number of training posts in ophthalmology. Hence optometrists in the UK have seen their roles and scope of practice extend along with legislative changes, notably along with independent prescribing in 2008. Several British studies have found good outcomes in optometryinvolved clinics in regard to management of glaucoma, minor eye conditions, diabetes and acute eye diseases. ${ }^{45}$

The overall number of ophthalmologists in Denmark has been slightly increasing during the last decade, on average 79 per million population, similar to most western continental European countries. ${ }^{6-8}$ On a global scale, the number of patients in eye care has risen dramatically during the last two decades, which has resulted in a shortage of eye care professionals globally. ${ }^{9}$ The Danish Patient Association for Prevention of Blindness, Fight for Sight (Øjenforeningen), reports a similar finding with a surge of $49 \%$ in the number of examined or treated eye patients in the primary sector in the age group of 60-74 years in the period from 2007 to 2016.

Strategies to combat inevitable waiting times for appointments by the Danish Healthcare System include implementing new technological systems, instituting new work patterns and/or training more eye care professionals. 6710

In the last 5 years, the majority of Danish optical companies have identified and filled this gap in the market, evolving from primarily offering refraction/anterior segment investigations towards providing their customers with a more comprehensive vision examination, which includes posterior segment fundus $45^{\circ}$ imaging, noncontact tonometry and visual field analysis. This trend is has been observed across most of Europe, particularly in the UK. ${ }^{11}$ This has received a mixed response from the primary eye care sector, particularly as increases in false positive referrals would negate any benefits gleaned from this service. ${ }^{12}{ }^{13}$ In order to address this, a telemedical ophthalmology service with an e-referral cloud-based platform model was implemented systematically for the optical company Louis Nielsen A/S's 77 stores. Although there has been some pilot studies on the applications of telemedicine, ${ }^{14}$ to the authors' knowledge, this is the first Nordic study and the largest in the field. ${ }^{15-17}$

The purpose of this study was to evaluate the follow-up and referral pattern after implementing the telemedical service (TS) for optometrists' suspected posterior segment pathology and further characterise the common and rare disease findings according to the referral pattern.

\section{MATERIAL AND METHODS}

Prior to the implementation of the TS, a pilot study was conducted to investigate the referral rate. This was done by one ophthalmologist in the period from 1 April 2018 to 1 May 2018. A total of 715 patients, whom the optometrist would have referred directly to the national eye care system, were instead referred to a telemedical setup with one ophthalmologist, who evaluated all cases. Major findings were $12.5 \%$ of the patients were referred to the national eye care system, $30.5 \%$ needed follow-up by the optometrist, $30 \%$ needed follow-up teleophthalmologically, while the remaining $16.5 \%$ did not need any further follow-up. This pilot study provided key insights in order to proceed with the study.

The setup was introduced, 1 June 2018, and has been fully operational since the 1 August 2018. This retrospective cohort study was based on all referrals to the TS in the period from 1 August 2018 to 31 July 2019.

Patients or the public were not involved in the design, or conduct, or reporting, or dissemination plans of our research.

The work complies with the criteria defined by the Declaration of Helsinki. Prior to sharing data via the cloud, mandatory consent to company policies and data processing were obtained from the patients. The data were extracted fully anonymously, hence no permission for the use of the data was necessary according to The Danish Data Protection Agency.

The e-referral platform was enabled using a multicentre storage cloud-based-imaging-software provided by Optoflow, Kide (Finland). Data registration and patient referral to the online national referral platform (REFHOST) that links to every general Danish ophthalmologist, GPs and rest of the healthcare sector, were provided by Novax A/S (Aarhus, Denmark). All data storage and data management comply with the General Data Protection Regulation Standards.

\section{The setup}

The setup is illustrated in the flow chart (figure 1). Any customer above 16 years who underwent refraction for spectacles (vision examination) were further offered a comprehensive optometrist examination that apart from refraction included non-contact IOP, slit lamp examination, fundus imaging and in relevant cases visual field analysis. The patient provided verbal consent prior to any examination.

All patients visiting a Louis Nielsen A/S store, who underwent a comprehensive optometrist vision examination and referred to TS, were registered in the cloud-based system Optoflow and fully available for the TS ophthalmologist. This included relevant patient history, best-corrected visual acuity without and with pinhole, intraocular pressure (IOP) by either rebound-tonometry (Icare, Helsinki, Finland) or non-contact-tonometry 


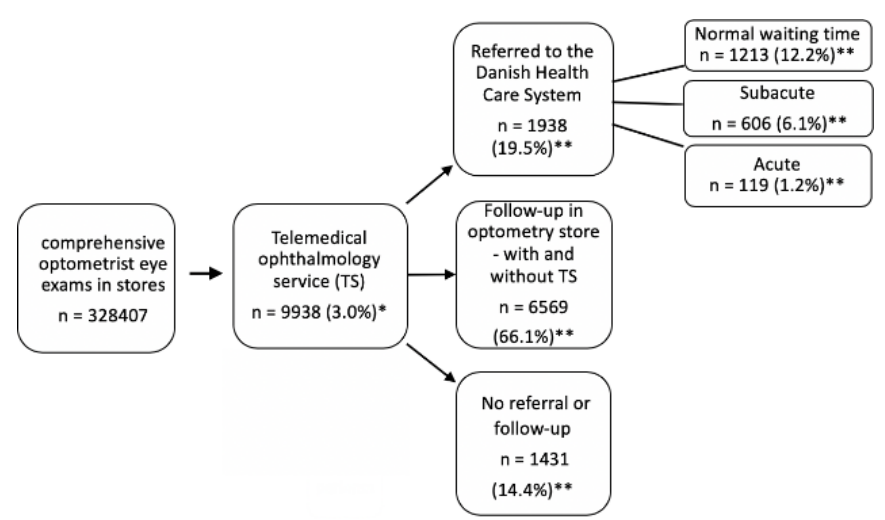

Figure 1 Flow chart illustrating the patient journey. Number of patients (n). *Represents the percentage of patients included in the telemedical service (TS) (9938) from the pool of total number of comprehensive optometrist vision examination in store (328407). ${ }^{\star \star}$ Represents the percentage of patients undergoing further stratification in the TS for either referral (different categories), follow-up and no referral/ follow-up from the total number of patients in TS (9938).

(Nidek Tonoref II/III, Japan), description of the slit lamp examination, $45^{\circ}$ colour fundus image (Centervue DRS, Italy), 4-in-1 visual-field-report (Haag-Streit Octopus 900, Switzerland) in relevant cases and a conclusion including a tentative International Classification of Diseases, 10th Revision (ICD-10) diagnosis.

All optometrists (total: 272) in all Louis Nielsen A/S stores were provided with referral guidelines that were based on the national referral guideline between optometrist and ophthalmologist from the Dania College of Optometry. ${ }^{18}$ A particular change in practice for optometrists were introduced in relation to all posterior segment diseases: when the optometrist wanted to refer a patient due to ocular posterior segment pathology, the optometrists complied to exclusively e-refer the patients to the TS. The optometrist referred the patient according to the three different suspected referral pathways: suspected acute (within 24 hours), suspected subacute (within 4 weeks) or suspected normal waiting time (non-acute). In suspected acute cases, the optometrist sought an immediate phone call-based consultation with an immediate action provided by the TS ophthalmologist. Suspected subacute cases were always reviewed on the same day, while normal waiting-time (non-acute) patients were examined within three working days by the TS ophthalmologist. The optometrists also complied to follow up on TS replies including patient contact within three working days in case of normal referrals and within 24 hours in subacute cases.

The TS consisted of 11 consultant ophthalmologists, registered in the specialist register by the Danish Patient Safety Authority. They all complied to a set of guidelines for referral to the Danish Eye Care Service that were aligned between the Danish Ophthalmology Society (Danske Øjenlægers Organisation) and mitØje ApS. Internal guidelines were implemented for the
TS ophthalmologists. Patient referrals were assigned randomly and evenly with no influence from the referring optometrist.

The TS ophthalmologist provided the optometrist with a description of the clinical findings, ICD10-diagnosis, follow-up/referral pathway plan and in relevant cases an e-referral on the national referral platform (REFHOST). The TS ophthalmologist's referrals to the national eye service were accordingly: All acute sight-threatening cases were immediately referred to the local tertiary eye/ neurology clinic, while subacute and normal waiting patients were referred to the general primary ophthalmologist.

According to a calculated power analysis, $2.5 \%$ of all ophthalmologist examinations in TS were re-evaluated by one single ophthalmologist on a weekly basis.

Exclusion criteria of this study were patients with already known ocular diseases with existing follow-up regimen with an ophthalmologist.

\section{Statistical methods}

Data from the Novax A/S (Aarhus) were exported to an Excel spreadsheet (Microsoft, Washington District of Columbia, USA) for statistical analyses. All normally distributed data mean values are reported with $95 \%$ CI.

\section{RESULTS}

A total of 386361 customers underwent a vision examination in the study period, and $85 \%$ of these customers, equivalent to 328407 customers, underwent a comprehensive optometrist vision examination from which 9938 patients $(3 \%)$ were enrolled into this study with optometrist suspected ocular posterior segment pathology. An even distribution of referrals according to the total number of vision tests were observed across all geographic locations $(\mathrm{p}<0.05)$.

No significant age difference between the customers who underwent a comprehensive optometrist vision examination and those referred to TS were found ( $p>0.05$ ): accordingly males were averagely 47.5 years, 95\% CI (20.3 to 69.3 ) and females were 45.4 years, $95 \%$ CI (20.0 to 74.0 ) vs males 55.5 years, $95 \%$ CI (36.2 to 70.3 ) and females 53.4 years, $95 \%$ CI (31.2 to 75.0 ). Further no significant difference in genders were observed.

Though average age between acute referrals (32.5 years, 95\% CI (29.2 to 61.3)) and non-acute referrals (54.5 years $95 \%$ CI (33.2 to 70.3)) were observed, this finding was also non-significant $(\mathrm{p}>0.05)$.

False negative review was performed in $2.5 \%$ of all TS ophthalmologist reviews and no significant change in diagnosis or plan was found.

\section{Time measurements}

The mean time spent from when the optometrist e-referred a suspected non-acute patient until the review was done by the TS ophthalmologist was on average 29 hours, $2 \mathrm{~min}$ and $28 \mathrm{~s} 95 \%$ CI (18.54.28 to 39.10.28). Mean time for the optometrist to communicate the TS 


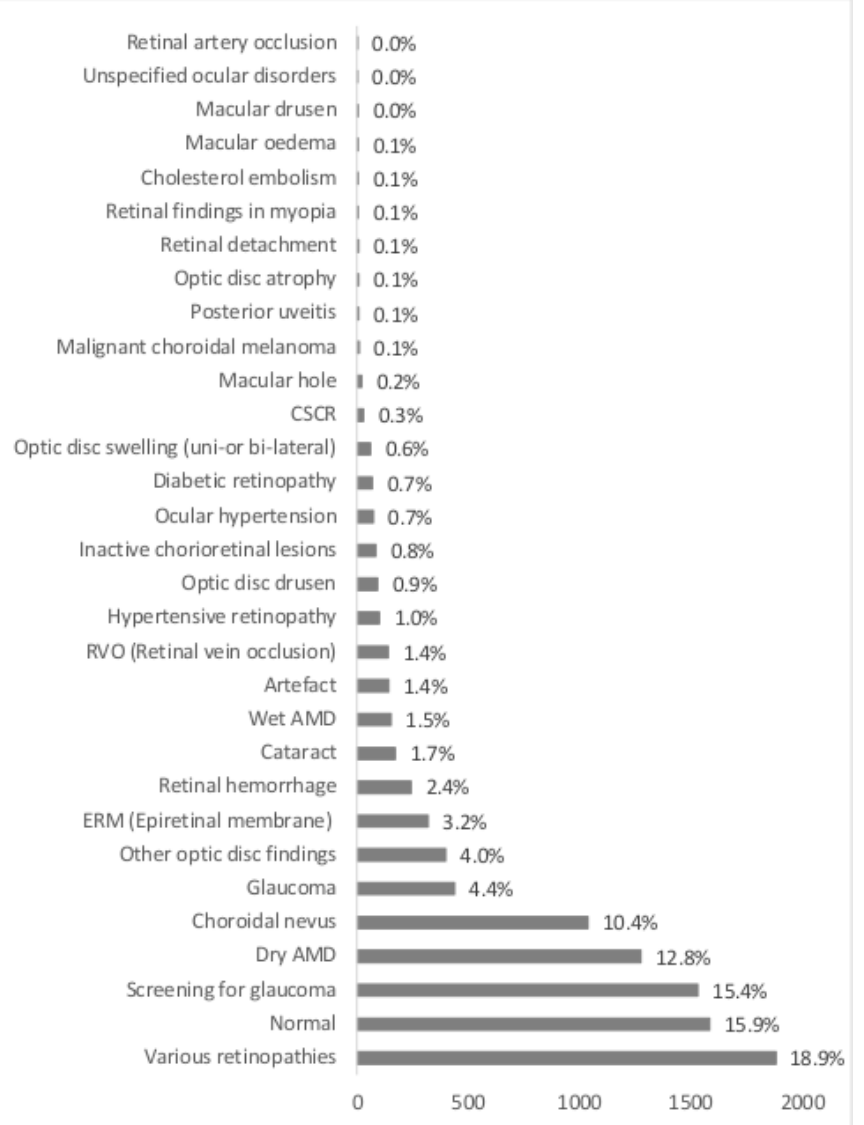

Figure 2 The total diagnoses TS ophthalmologist among patients who were included in the study. Total number of patients included in this study were 9938. TS, telemedical service.

ophthalmologist diagnosis and follow-up plan to the nonacute patient was 55 hours, $1 \mathrm{~min}$ and $31 \mathrm{~s} 95 \% \mathrm{CI}$ (39.1.20 to $96 ; 71.1 .20)$. The average non-acute patient journey time was 115 hours, 18 minutes, $1 \mathrm{~s} 95 \%$ CI (46.18.1 to 184.18.1).

As optometrists used the phone-service for immediate action similar time journeys were not measurable for acute and subacute patients.

\section{Follow-up and referral pathways in TS}

As illustrated in figure 1, the TS referred $19.5 \%$ (1938) of the patients to the Danish national eye service, while $80.5 \%$, equivalent of 8000 patients, were not referred in the period from 1 August 2018 to 31 July 2019. 14.4\% (1431 patients) of the referrals in TS did not need any further follow-up, while a majority of $66.1 \%$ (6569 patients) needed some follow-up either by the optometrist themselves (46.8\% (4651 patients)) or by follow-up within the TS (19.3\% (1918 patients)).

\section{Referral characteristics}

The most frequent TS ophthalmologist findings among the optometrist referrals to the TS were in $78 \%$ of the cases: various retinopathy (the largest group, representing a broad mix of various retinal changes that range from benign, age related to disease-associated risk factors), normal (optometrist suspected posterior segment disease, that were ruled out by TS ophthalmologist), screening for glaucoma (patients with risk factors requiring glaucoma monitoring (visual field, optic disc evaluation and IOP-measurement), but with no sign of glaucomatous damage), glaucoma (based on ocular history, optic disc evaluation on fundus and visual fields over time), dry age-related macula degeneration (AMD) and choroidal nevus (figure 2). Meanwhile, TS referrals to the general ophthalmologists within the normal waitingtime were in around half the cases due to screening for glaucoma, various retinopathy, glaucoma, dry AMD and cataract (figure 3). Noticeable is that the diagnosis cataract was often found in patients referred with suspected posterior segment disease, and in these cases it was diagnosed by the TS ophthalmologist based on the ocular history, visual acuity with and without pinhole, change in refraction, slit lamp examination description and clearness of the fundus images.

Approximately one-fourth of the subacute referrals were due to wet AMD (figure 4), while papillary oedema (bilateral in $85 \%$ of the cases) was the most common referred diagnosis within 24 hours (acute) (figure 5). A much less prevalent acute reason for referral was IOP above $30 \mathrm{~mm} \mathrm{Hg}$ (ocular hypertension) (figure 5).

Approximately $50 \%$ of the optometrist follow-ups (both with and without TS) are related to ocular hypertension, dry AMD and choroidal nevus. The other half being various retinopathies.

\section{DISCUSSION}

The number of patients enrolled in TS (9938) are from a larger pool of customers undergoing a comprehensive optometrist vision examination (328 407), which accounts for $85 \%$ of the total number of customers for vision examinations. As the optometrist comprehensive vision examination is offered at no additional charge, the authors believe the most likely explanations for the remaining customers $(15 \%)$ are: age less than 16 years old, customers already enrolled into the national eye care system or customers, who simply didn't have the time or desire for further testing.

Posterior segment diagnoses were similar to what is shown in other national studies. ${ }^{19-26}$ However, a relatively high number of bilateral papillary oedema patients were observed in this study; a likely consequence that patients with 'headache' seen by GPs are often sent directly to an optometrist.

The most common TS referral diagnoses to the general ophthalmologist were glaucoma (diagnosed by evaluation of optic disc, IOP and visual field) and glaucoma screening (patients with severe risk of glaucoma development), which accounted for a total of one-fourth of all patients referred within a normal waiting time (nonacute). The overall prevalence of glaucoma in Denmark is estimated to $3.76 \%$ in the age group above 50 years and close to $50 \%$ of all primary open angled glaucoma patients are estimated to be unrecognised. This study 


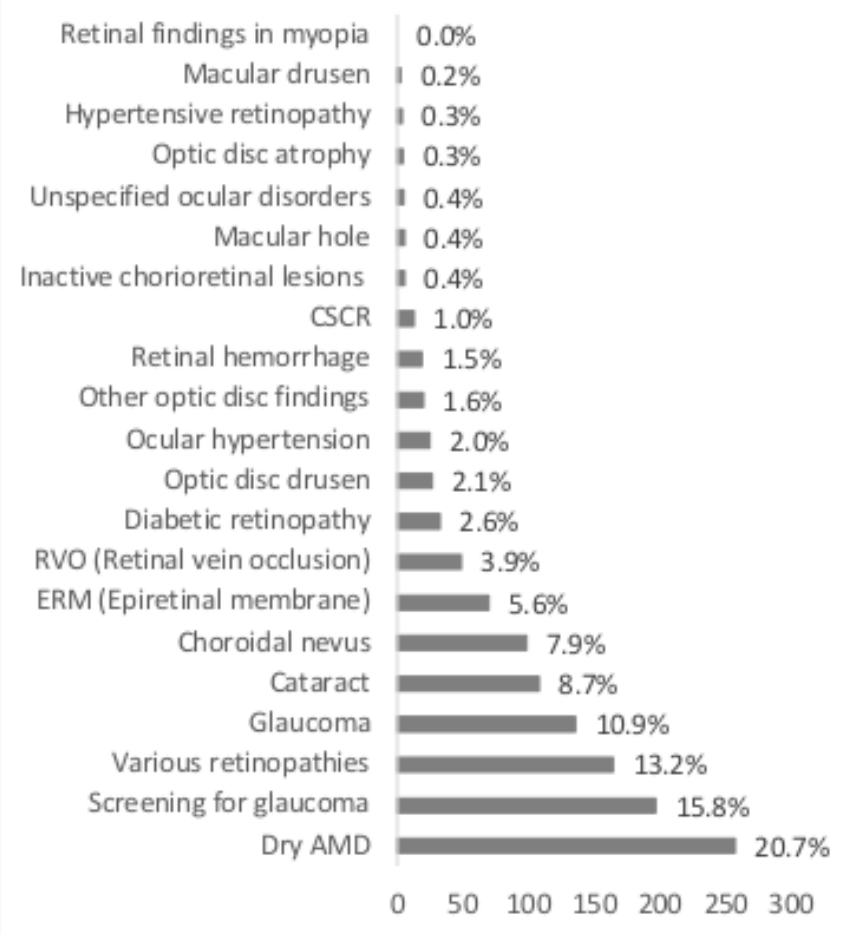

Figure 3 The most common diagnoses by TS ophthalmologist among patients referred as normal waiting time to the healthcare sector. Total no of patients 1242. CSCR, Central Serous Chorioretinopathy; ERM, epiretinal membrane; TS, telemedical service.

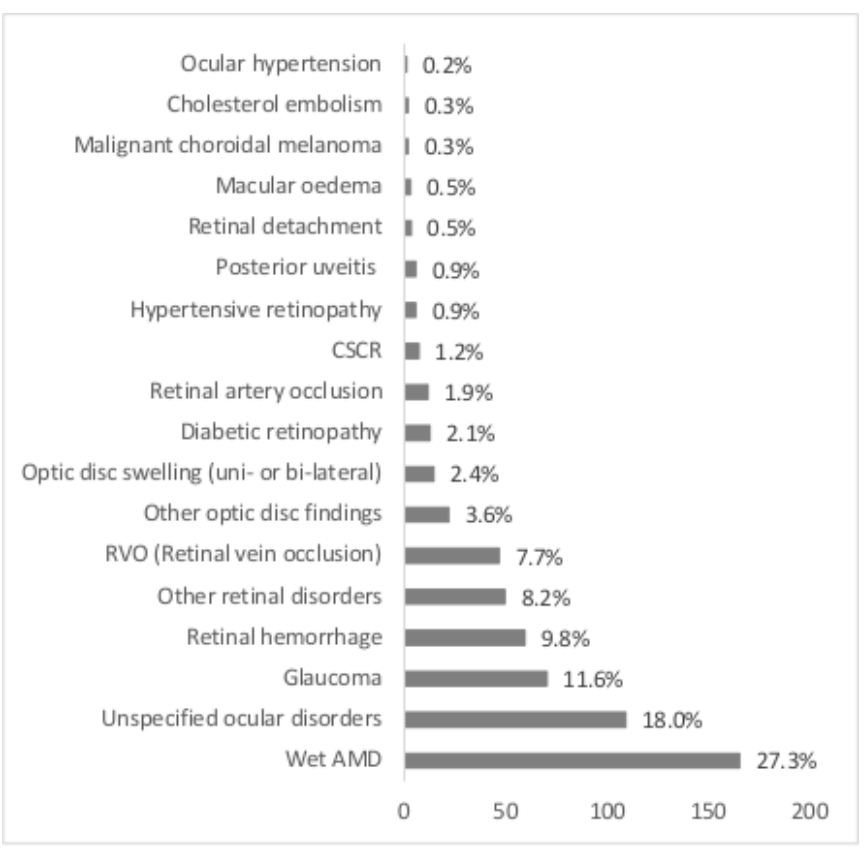

Figure 4 The most common diagnoses by TS ophthalmologist among patients referred as subacute to the healthcare sector. Total no of patients 606 . TS, telemedical service.

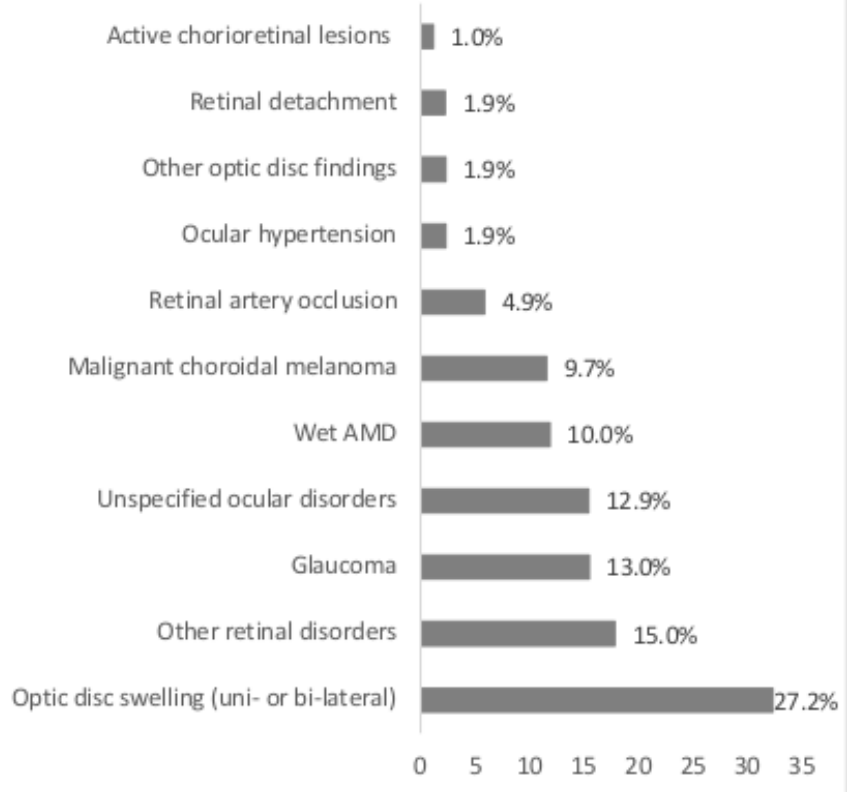

Figure 5 The most common diagnoses by TS ophthalmologist among patients referred as acute to the healthcare sector. Total no of patients 119. TS, telemedical service.

also highlights that unrecognised glaucoma is an issue that needs further awareness. ${ }^{27-31}$

Three per cent of the total number of patients undergoing an optometrist comprehensive vision examination in Louis Nielsen A/S were referred for ophthalmologist review in TS in this study. This was consistent with the overall optometrist referral rate in Denmark, and can vary tremendously between countries, from $3 \%$ to $14 \%$. ${ }^{19} 202325$ Thus, we consider a posterior segment disease referral rate between $2.5 \%$ and $4 \%$ to a TS as adequate, while, along with such a TS, a referral-ratio between $0.5 \%$ and $1.0 \%$ to the national eyecare system would be considered sufficient.

To our knowledge, TS is the world's largest optometristophthalmologist cloud-based e-referral platform based on the number of reviewed patients. It is particularly unique due to the fact that Louis Nielsen A/S with its high customer market share, close to $47 \%$ and widespread locations across the country, represents patients from different demographic and socioeconomic backgrounds. In addition, Louis Nielsen A/S is a major employer of Danish optometrists graduated from either of the two Danish optometry colleges. ${ }^{30} 32$ Though the results may be extrapolated to the overall Danish optometry competency, the authors advise caution in generalising the findings to the overall Danish optometry standard due to lack of demographic information on the national optometry cohort. Further the authors also acknowledge that the selected minority of Danish optometrists that are involved in the healthcare sector are differently qualified. Also previous research from the UK has indicated that there are differences in the outcomes from eye 
examinations conducted in independent and corporate practises. ${ }^{33}{ }^{34}$ However, a recent questionnaire study in Northern Europe (Denmark, Sweden, Norway, Finland and the Netherlands), concludes that there is a similar level of optometry competency across the countries and further there is only a minor difference between new and experienced optometrists with more than 5 years of practising. ${ }^{35}$ Supported by these factors, the authors suggest that this study is highly relevant for any optometry retail company in the region.

As all major optical companies have implemented fundus cameras, non-contact tonometers and automated perimeters, ${ }^{12} 36$ this study provides critical outcome measures of what it would look like, if TS was to be implemented on a nationalwide scale. Though the initial pilot study supports the study referral outcomes, the authors advice some caution in extrapolating the findings and suggest that the TS implementation reduced the number of referrals with maximum 8000 patients in the study period.

Clearly, an up to $81 \%$ reduction of referrals to the primary and tertiary eye-care sector with the TS setup is remarkable, but it does not imply that optometrists are referring only false positive patients. In fact, this study demonstrates that only $14.4 \%$ were normal cases. The consequence of the widespread availability of newer technological instruments is the increased detection of asymptomatic pathological and moderate-to-risk findings that do not require medical intervention (eg, glaucoma screening patients). ${ }^{15}$ In these cases, depending on risk of disease transformation, the patient would be stratified for follow-up in-house either with or without TS. In both follow-up patterns the optometrist would be provided with a patient-specific examination, follow-up and action plan by the TS ophthalmologist. Some countries, as the UK, have developed collaborative hospital eye service (HES)-referral guidelines in order to structure the referrals from optometrists. However, studies evidently point out that guidelines alone do not sufficiently address the number of unnecessary referrals. ${ }^{17}$ Cameron $e t$ al found that $37 \%$ of all optometric HES-referrals were false positive within the NHS. Further, Kern et al reported that the newly implemented optometrist-ophthalmologist e-referral platform at the Moorfield's Eye Hospital, based on 107 patients, shows a reduction of 50\% in referrals from optometrists, in spite of implemented HES guidelines. Similarly, we also believe it is crucial to acknowledge that the national eye care should focus on the true ill patient, which becomes more achievable with new models, as demonstrated.

The authors, therefore, suggest that the TS setup provides a relevant stratification model for the moderate/ high risk or asymptomatic non-treatable conditions, with a closed in-house telemedical follow-up service and lean referral pathways for the treatable conditions. The average time from the patient referral to review by the TS ophthalmologist was immediate by phone service in acute patient cases and averagely close to only 1.2 days in suspected non-acute patient cases. In acute situations, for example, papillary oedema and retinal detachment, patients were directly contacted by the TS ophthalmologist and admitted to the relevant tertiary clinics (neurology or ophthalmology). This service further shortens the otherwise cumbersome traditional patient healthcare pathway, where patients often have to be examined by both the GP and general ophthalmologist (primary sector) in order to be referred to the tertiary centre. All referred patients benefit from a TS ophthalmologist written e-referral letter uploaded to the national referral platform (REFHOST), making the e-referral available for any healthcare authority in Denmark. This provides a better opportunity for the general ophthalmologist to triage the patient, which may reduce the time for review and treatment, for example, for subacute diagnoses as wet-AMD where waiting time causes visual impact. $^{37}$

Telemedicine in ophthalmology is a very well proven concept with several well-run services as for AMD and diabetic retinopathy. ${ }^{38}$ However, telemedicine should not only serve relevantly in ophthalmology units, but also as a well-suited model for optometrist posterior segment referrals. The optometrists in all the Nordic countries have in recent years implemented instruments for posterior segment investigation, and newer technologies are becoming increasingly more affordable, for example, UK Specsavers (Saint Andrew, UK) implemented optical coherence tomography (OCT) devices in all of its 740 locations. ${ }^{39}$ Due to the general life span increase among their populations, Nordic and British societies as well are struggling to manage the increased number of patients. Hence, it is highly relevant to find a cost-effective solution. This telemedical setup proves to be an efficient system to improve the referral to the healthcare system. Further, the authors believe this service may serve as a fundament for implementation and validation of newer technologies, that are based on the concept of pattern recognition and deep-mind based automated diagnoses with OCT and fundus technology. ${ }^{38} 40-43$

Nevertheless, there are some limitations in this study, which are essential to address in future studies. Though it was not the aim of this study to directly evaluate the optometry competency, it is highly relevant to evaluate the optometrist's diagnostic precision level in various diseases over time and to investigate the false negatives in the optometrist cohort. Also additional patient information is relevant, for example, visual acuity and pharmacological history, in order to increase our understanding of the results. Further, it is relevant to characterise the referrer's as well as the reviewing ophthalmologists more individually, and based on other factors such as years of experience and qualifications. This kind of demographic information on optometrists are necessary in order to compare findings with other cohorts.

The knowledge from such future studies can be utilised in continuous educational programmes. 
In conclusion, we report the results from the largest e-based optometrist-ophthalmologist referral platform study to date. Overall, posterior segment disease referrals to the existing healthcare system can be drastically reduced. This study demonstrates that new healthcare models, which focus on a risk-stratified approach with optimal use of technology, change of working patterns and continuous education, can further optimise the healthcare system.

Acknowledgements The authors would like to thank Martin Mølgaard and Pouline Lie for their assistance with the data management and technical support.

Contributors DVM and HB created and manage the service from either side. All listed authors contributed to the acquisition, analysis or interpretation of data for the work, drafted or revised the work critically for important intellectual contented.

Funding The authors have not declared a specific grant for this research from any funding agency in the public, commercial or not-for-profit sectors.

Competing interests DVM is the instigator for the concept development, implementation of the TS and founder of mitØje ApS. DVM further reports personal fees from Alcon in the study period. HB is the Head of Professional Advancement at Louis Nielsen A/S, part of Specsavers. MN is the Director of Louis Nielsen A/S, part of Specsavers. DS reports personal fees from Big Picture Eye Health, Allergan, Novartis and Bayer. All authors disclose no other relationships or activities that could appear to have influenced the submitted work.

Patient and public involvement Patients and/or the public were not involved in the design, or conduct, or reporting, or dissemination plans of this research.

Patient consent for publication Not required.

Ethics approval The study is classified as quality assessment according to local guidelines.

Provenance and peer review Not commissioned; externally peer reviewed.

Data availability statement Data are available upon request.

Open access This is an open access article distributed in accordance with the Creative Commons Attribution Non Commercial (CC BY-NC 4.0) license, which permits others to distribute, remix, adapt, build upon this work non-commercially, and license their derivative works on different terms, provided the original work is properly cited, appropriate credit is given, any changes made indicated, and the use is non-commercial. See: http://creativecommons.org/licenses/by-nc/4.0/.

ORCID iD

Danson Vasanthan Muttuvelu http://orcid.org/0000-0003-4304-9704

\section{REFERENCES}

1 Baldwin S. Healthcare systems around the world. Global Health 2011;4 https://web.b.ebscohost.com/abstract?direct=true\& profile $=$ ehost $\&$ scope $=$ site\&authtype $=$ crawler\&jrnl $=1937514 X \& A N=$ 79850460\&h=41DYlzTk0xNoapoSGfKx5evcY2U29xZrhRkmtzI\% 2fkg\%2ftn5xYeJCRnF59AEJidY4N5JpEgrdcdCw8ggU9w bylbQ\%3d\%3d\&crl=c\&resultNs=AdminWebAuth\&resultLocal= ErrCrINotAuth\&crlhashurl=login.aspx\%3fdirect\%3dtrue\%26profile\% 3dehost\%26scope\%3dsite\%26authtype\%3dcrawler\%26jrnl\% 3d1937514X\%26AN\%3d79850460

2 Ministry of health. Healthcare in Denmark an overview 2 Colophon healthcare in Denmark -an overview, 2017. Available: http://www. sum.dk [Accessed 25 Mar 2020].

3 Bartholdy B. Da optikerne blev TIL optometrister, 2019. Available: https://ojenforeningen.dk/sites/ojenforeningen.dk/files/media/ dokumenter/2019-12/Optometrister.pdf [Accessed 29 Mar 2020].

4 Crown J. Review of prescribing, supply and administration of medicines. Final Report. Crown II Report 1997.

5 Todd D, Bartlett $\mathrm{H}$, Thampy R, et al. Agreement in clinical decisionmaking between independent prescribing optometrists and consultant ophthalmologists in an emergency eye department. Eye 2020;34:2284-94.

6 Resnikoff S, Felch W, Gauthier T-M, et al. The number of ophthalmologists in practice and training worldwide: a growing gap despite more than 200,000 practitioners. Br J Ophthalmol 2012;96:783-7.
7 Resnikoff S, Lansingh VC, Washburn L, et al. Estimated number of ophthalmologists worldwide (international Council of ophthalmology update): will we meet the needs? Br J Ophthalmol 2020;104:588-92

8 Vittrup M, Steen-Andersen AM. Send flere penge, Tak! Værn om Synet 2019;02.

9 United Nations. Department of Economic and Social Affairs, Population Division, World Population Ageing. 2015.ST/ESA/ SER.A/390.

10 sundhed.dk V-. Available: https://www.sundhed.dk/borger/ behandling-og-rettigheder/sygehusvalg/ventetider/ [Accessed 1 Jan 2020]

11 Smith SJ. Delivering OPTOMETRIC care in the UK 2011.

12 Lichscheidt E, Nielsen F. Øjenlæger: "Optikerne sender alt for mange videre til os efter sundhedstjek" | Østjylland | DR, 2019. Available: https://www.dr.dk/nyheder/regionale/oestjylland/oejenlaegeroptikerne-sender-alt-mange-videre-til-os-efter [Accessed 1 Jan 2020].

13 Meyer I. Øjenlæger: Optikerkædes sundhedstjek giver nervøse patienter. Berlingske Nyhedsbureau, 2015. Available: https://www. berlingske.dk/samfund/oejenlaeger-optikerkaedes-sundhedstjekgiver-nervoese-patienter [Accessed 1 Jan 2020].

14 Bodnar ZM, Schuchard R, Myung D, et al. Evaluating new ophthalmic digital devices for safety and effectiveness in the context of rapid technological development. JAMA Ophthalmol 2019;137:939-44.

15 Cameron JR, Ahmed S, Curry P, et al. Impact of direct electronic optometric referral with ocular imaging to a hospital eye service. Eye 2009;23:1134-40.

16 Kern C, Kortuem K, Hamilton R, et al. Clinical outcomes of a hospital-based Teleophthalmology service: what happens to patients in a virtual clinic? Ophthalmol Retina 2019;3:422-8.

17 Kern C, Fu DJ, Kortuem K, et al. Implementation of a cloud-based referral platform in ophthalmology: making telemedicine services a reality in eye care. Br J Ophthalmol 2020;104:1-6.

18 Damgaard Buchholt H, Dania Randers E. Guidelines for optimering AF optometristers henvisning AF patienter TIL øjenlaege. Available: www.eaDania.dk [Accessed 29 Jan 2021].

19 Sundling V, Gulbrandsen P, Bragadottir R, et al. Optometric practice in Norway: a cross-sectional nationwide study. Acta Ophthalmol Scand 2007;85:671-6.

20 Dobbelsteyn D, McKee K, Bearnes RD, et al. What percentage of patients presenting for routine eye examinations require referral for secondary care? A study of referrals from optometrists to ophthalmologists. Clin Exp Optom 2015;98:214-7.

21 Parkins DJ, Benwell MJ, Edgar DF, et al. The relationship between unwarranted variation in optometric referrals and time since qualification. Ophthalmic Physiol Opt 2018;38:550-61.

22 Baker H, Ratnarajan G, Harper RA, et al. Effectiveness of UK optometric enhanced eye care services: a realist review of the literature. Ophthalmic Physiol Opt 2016;36:545-57.

23 Brin BN, Griffin JR. Referrals by optometrists to ophtholmologists and other providers. J Am Optom Assoc 1995;66:154-9 http://www. ncbi.nlm.nih.gov/pubmed/7730556

24 Pierscionek TJ, Moore JE, Pierscionek BK. Referrals to ophthalmology: optometric and general practice comparison. Ophthalmic Physiol Opt 2009;29:32-40.

25 Lundmark PO, Luraas K. Survey of referrals and medical reports in optometric practices in Norway: midterm findings from a 3-year prospective Internet-based study. Clin Optom 2017;9:97-103.

26 Davey CJ, Green C, Elliott DB. Assessment of referrals to the hospital eye service by optometrists and GPs in Bradford and Airedale. Ophthalmic Physiol Opt 2011;31:23-8.

27 Sommer A, Tielsch JM, Katz J, et al. Relationship between intraocular pressure and primary open angle glaucoma among white and black Americans. The Baltimore eye survey. Arch Ophthalmol 1991;109:1090-5.

28 Lundberg LU, Thygesen J, Damgaard-Jensen L, et al. [Glaucoma patients treated by practicing ophthalmologists in Denmark. Estimated number of patients and the extent of visual field defects]. Ugeskr Laeger 2000;162:3028-33 http://www.ncbi.nlm.nih.gov/ pubmed/10850191

29 Kolko M, Horwitz A, Thygesen J. The prevalence and incidence of glaucoma in Denmark in a fifteen year period a nationwide study. 2015.

30 Sundhedsydelser skal løfte Louis Nielsen videre | Louis Nielsen. Available: https://via.ritzau.dk/pressemeddelelse/sundhedsydelserskal-lofte-louis-nielsen-videre?publisherld=11113033\&releaseld= 11253073 [Accessed 30 Jan 2021].

31 Heijl A, Bengtsson B, Oskarsdottir SE. Prevalence and severity of undetected manifest glaucoma: results from the early manifest glaucoma trial screening. Ophthalmology 2013;120:1541-5. 
32 Villiaze L, Andrew' S. Specsavers 2019.

33 Swystun AG, Davey CJ. Exploring the effect of optometrist practice type on NHS funded sight test outcome. J Optom 2021;14:69-77.

34 Shah R, Edgar DF, Rabbetts R, et al. The content of optometric eye examinations for a young myope with headaches. Ophthalmic Physiol Opt 2008;28:404-21.

35 Tindlund S. Klinisk Kvalitet: ER det forskjeller mellom optikere I nord-Europa? Optikerne 2020:38-41 https://www.optikerne.no/ getOptikeren.php?ID=48685461\&issue=Optikeren20206 (accessed 30 Jan 2021).

36 Vittrup M, Steen-Andersen AM. Send flere penge, Tak! Værn om Synet 2019.

37 Bloch SB, la Cour M, Sander B, et al. Predictors of 1-year visual outcome in neovascular age-related macular degeneration following intravitreal ranibizumab treatment. Acta Ophthalmol 2013;91:42-7.

38 Rathi S, Tsui E, Mehta N, et al. The current state of Teleophthalmology in the United States. Ophthalmology 2017;124:1729-34.
39 McCormick E. An OCT in every Specsavers announced, 2018. Available: https://www.aop.org.uk/ot/industry/high-street/2018/11/ 19/an-oct-in-every-store-by-2020 [Accessed 1 Jan 2020].

40 De Fauw J, Ledsam JR, Romera-Paredes B, et al. Clinically applicable deep learning for diagnosis and referral in retinal disease. Nat Med 2018;24:1342-50.

41 Schlegl T, Waldstein SM, Bogunovic $\mathrm{H}$, et al. Fully automated detection and quantification of macular fluid in OCT using deep learning. Ophthalmology 2018;125:549-58.

$42 \mathrm{Li} \mathrm{F}$, Chen H, Liu Z, et al. Fully automated detection of retinal disorders by image-based deep learning. Graefes Arch Clin Exp Ophthalmol 2019;257:495-505.

43 van der Heijden AA, Abramoff MD, Verbraak F, et al. Validation of automated screening for referable diabetic retinopathy with the IDx-DR device in the Hoorn diabetes care system. Acta Ophthalmol 2018;96:63-8. 